\title{
Atmospheric pathway between Atlantic multidecadal variability and European summer temperature in the atmospheric general circulation model ECHAM6
}

\author{
Rohit Ghosh ${ }^{1}$ (] - Wolfgang A. Müller ${ }^{2,3}$ - Astrid Eichhorn ${ }^{4}$. Johanna Baehr ${ }^{5}$. Jürgen Bader ${ }^{2,6}$
}

Received: 29 December 2017 / Accepted: 6 December 2018 / Published online: 17 December 2018

(c) The Author(s) 2018

\begin{abstract}
The Atlantic multidecadal variability (AMV) is known to affect the central to eastern (C-E) European summer climate through an associated atmospheric baroclinic response called North-Atlantic-European East West mode as demonstrated in the twentieth century reanalysis (20CRv2). Here, using the atmospheric model ECHAM6.3, we perform sensitivity experiments with prescribed sea surface temperature (SST) anomalies that are representative of the observed positive and the negative AMV phases and investigate the model response to the observed AMV pattern for European summer climate. The results from the experiments reveal that in the negative phase of AMV, the North-Atlantic-European (NAE) climate is mainly governed by the extra-tropical branch of the AMV through a baroclinic-like response. This response brings negative surface air temperature (SAT) anomalies over C-E Europe. The response and its influence are similar to what is found in the 20CRv2. In contrast, in the positive phase of the AMV, the NAE climate in the model experiments is mainly influenced by the tropical branch of the AMV. A stationary Rossby wave response excited in the tropics is associated with negative SAT anomalies over C-E Europe, which is opposite to what is found in the 20CRv2. The model response from the tropical part of the AMV SST is unlikely to be realistic due to the lack of coupled air-sea interaction, when SST is specified. Hence, the results demonstrate that ECHAM6.3 can simulate the observed linear baroclinic response, but only in the negative phase of the AMV. For the positive phase, in agreement with the previous findings, the model response is very sensitive to the tropical branch of the AMV and unrealistic.
\end{abstract}

Keywords Atlantic multidecadal variability $\cdot$ Summer $\cdot$ Europe

\section{Introduction}

Using the twentieth century reanalysis (20CRv2) (Compo et al. 2011), the observed atmospheric pathway between Atlantic multidecadal variability (AMV) and central to eastern (C-E) European summer (June-August, JJA) climate has been identified by an east-west wave like sealevel pressure (SLP) pattern, named North-Atlantic-European East West (NEW) mode (Ghosh et al. 2017). These authors showed that the diabatic heating in the north-western Atlantic Ocean induces a linear baroclinic response with a low-pressure anomaly east of the heating and an east-west wave like response associated with it, which they refer as the

Rohit Ghosh

rohit.ghosh@mpimet.mpg.de

Extended author information available on the last page of the article
NEW mode. The NEW mode affects the European climate by favoring blocking-like situation over the $\mathrm{C}-\mathrm{E}$ Europe in the positive AMV phase and vice-verse. Other studies also identify the same observed atmospheric pathway from AMV, which eventually affects the European as well as the rest of the northern hemispheric land-surface temperature on decadal time scales (Wu et al. 2016a, b). Here, we investigate the atmospheric pathway between AMV and European summer climate in an atmospheric model, ECHAM6.3 and examine to what extent the model response can replicate the characteristics of the observed NEW mode.

Some previous studies suggest that the summer atmospheric response to AMV is similar to the winter response (Terray and Cassou 2002; Davini et al. 2015). Their suggested response to the positive phase of AMV in winter is related to the stationary Rossby wave generation from the diabatic heating in the western tropical Atlantic, which increases the transient eddy feedback to the mean flow and 
shifts the mean position of the mid-latitude storm track equator-ward. The alteration of the mean storm track position influences the climate over the North Atlantic-European (NAE) region. However, a recent study based on 20CRv2 shows that the eddy activity is much weaker in summer than in winter (Ghosh et al. 2017).

Regarding the summer response, many studies focused mainly on the impact of the tropical branch of the AMV on the surrounding continents (Sutton and Hodson 2007; Hodson et al. 2010). As an example Hodson et al. (2010) used five atmospheric general circulation models (GCMs) and performed idealized simulations with the forcing of averaged positive and negative phases of AMV SST anomalies. The simulations are different from the previous idealized simulations in using seasonally varying AMV SST anomalies such as Rodwell et al. (1999). Hodson et al. (2010) revealed a consistent impact from the tropical branch of the AMV on the northern part of South America and on the United States. The response was attributed to a combination of the off-equatorial Gill-type response to diabatic heating over the western tropical Atlantic due to increased precipitation (Gill 1980) and the northward shift of the Inter-tropical Convergence Zone (ITCZ) due to an anomalous cross-equatorial SST gradient. The off-equatorial Gill-type response to diabatic heating is the reason for the stationary Rossby wave generation in the tropics, which propagates to the extra-tropics and influences the mid-latitude summer climate. However, Hodson et al. (2010) did not show any robust relation between AMV and NAE climate and specifically European summer climate from their simulations.

Regardless of the model results from the tropical AMV forced experiments, it should be noted that the response from the SST forced experiments is only valid when the SST is ocean driven. There is growing evidence of the tropical part of the AMV being atmosphere driven (Brown et al. 2016; Yuan et al. 2016; Drews and Greatbatch 2016, 2017). The cloud radiative feedback is suggested to be the main driver of the tropical part of the AMV (Brown et al. 2016). The weakened trade wind in response to the warm extra-tropical part of the AMV reduces the low cloud fraction and brings warmer AMV SST over the tropics (Yuan et al. 2016). Therefore, prescribing the tropical part of the AMV could lead to unrealistic responses and might affect the response from other part of the AMV.

Other studies indeed found a linear baroclinic response from the diabatic heating of the extra-tropical Atlantic ocean in the idealized model simulations and also from a limited observational record (Hoskins and Karoly 1981; Kushnir 1994; Kushnir and Held 1996). According to their findings, following a linear quasi-geostrophic theory, a shallow diabatic heating from the midlatitude SST anomalies can induce a surface low east of the heating region as baroclinic response (Hoskins and Karoly 1981). Further, a similar response is found for the interdecadal variations of the SST in the extratropical Atlantic ocean over all seasons from limited observational record (Kushnir 1994). Additionally, the atmospheric GCM experiment with prescribed SST anomalies over the extra-tropical Atlantic Ocean showed similar results (Kushnir and Held 1996). However, their response was much weaker than observed. On top of that, forcing the model with the tropical part of the North Atlantic SST anomalies, which are atmosphere driven, could influence the characteristic of the response over the NAE region in an unrealistic way. This motivates us to further investigate the model response from the summer AMV and its link to the European climate, by performing well designed Atmospheric Model Inter-comparison Project (AMIP)-type experiments.

The AMIP-type experiments with AMV forcing have previously been performed to study the atmospheric response during summer (Sutton and Hodson 2005, 2007). Those experiments are conducted with the AMV forcing separately applied to the tropical, extra-tropical and combined for both the positive and the negative AMV phases. Over the mid-latitude region, the results from those experiments have shown an equivalent barotropic vertical structure of the geopotential height in the positive AMV phase and a baroclinic structure in the negative AMV phase. This indicates an overall nonlinear response to AMV over the NAE region. The positive phase response is indicated to be linked with the stationary Rossby wave emanating from the tropical part of the AMV. However, the negative phase response was not attributed to any mechanism, which we hypothesize as the observed baroclinic response from mid-latitude AMV [the NEW mode as shown in Ghosh et al. (2017)]. However, a rigorous analysis is still lacking to plausibly confirm our hypothesis about the model responses for the positive and negative phases of the AMV over the NAE region and especially over Europe. Hence, here we investigate the model response from the AMV in the positive and negative phases and compare it with 20CRv2 to understand if the model can simulate the observed response. If it can, then we try to figure out if the mechanism is similar to the proposed mechanism from 20CRv2 in Ghosh et al. (2017). If it can not, then we try to figure out what are the responses in the model that manifests differently than in 20CRv2. These responses can be related to the atmospheric model constraints from the lack of interactive SST and also could be due to the model biases. Altogether, through this thorough analysis of the model responses to the AMV over the NAE region, we can provide more insight about to which extent an atmospheric model can reproduce the observed pathways from AMV to European summer climate.

The details of all the AMIP-type experiments and the methods applied to analyze the outcomes can be found in Sect. 2. The SAT response over Europe from all the experiments are described in Sect. 3.1. The corresponding 
atmospheric pathways from the North Atlantic negative and positive AMV SST anomalies to the European SAT anomalies are explained in Sects. 3.2 and 3.3, respectively. Section 4 consists of a discussion of the results found in the experiments and the summary of all the main results from our study is provided in Sect. 5 .

\section{Experiments and methods}

The atmospheric component of the MPI-ESM, ECHAM6.3 is used for the sensitivity experiments. We use the low resolution (LR) version of the model with spectral resolution of T63 ( $92 \times 196$ grid points per lat/lon) and 47 vertical levels. A control simulation is performed, which is forced by global climatology of monthly-mean SSTs and sea-ice concentrations. The climatology is derived from the Hadley Center Sea Ice and Sea Surface Temperature (HadISST) data set over the period 1979-2008 (Rayner et al. 2003). The simulation is integrated for 50 model years, where the observed climatological SST forcing has been repeated every year. Hence, the 50 years of simulations can be considered as 50 sample members.
Next, six sensitivity experiments are performed, where the monthly AMV-like SST anomaly patterns are added on top of the monthly climatological SST. The monthly AMVlike SST anomaly patterns are prepared using the HadISST data, spanning from 1870 to 2014. First, we constructed the AMV index for each month. The monthly AMV index is defined as the 11-year running mean time series of the monthly averaged, detrended North Atlantic SST anomalies over the region $35^{\circ} \mathrm{N}-50^{\circ} \mathrm{N}$. This region is selected as a representative of the AMV index, following the study of Gulev et al. (2013). Further, the monthly AMV SST anomaly patterns are constructed by making positive and negative composites over the North Atlantic Ocean, based on the monthly AMV index. The positive and negative composites are the averaged, detrended SST anomaly states of all those years, when the AMV index was above and below +1 and -1 standard deviation, respectively. They are referred to as the AMV positive and negative phases in the experiments (Fig. 1).

We choose a specific region for each AMV sensitivity experiment. The AMV SST anomaly pattern has first been applied from $0^{\circ}$ latitude to $60^{\circ} \mathrm{N}$, referred to as ENTIRE hereafter. Due to the presence and variations of the prescribed monthly climatological sea ice, we mask out the
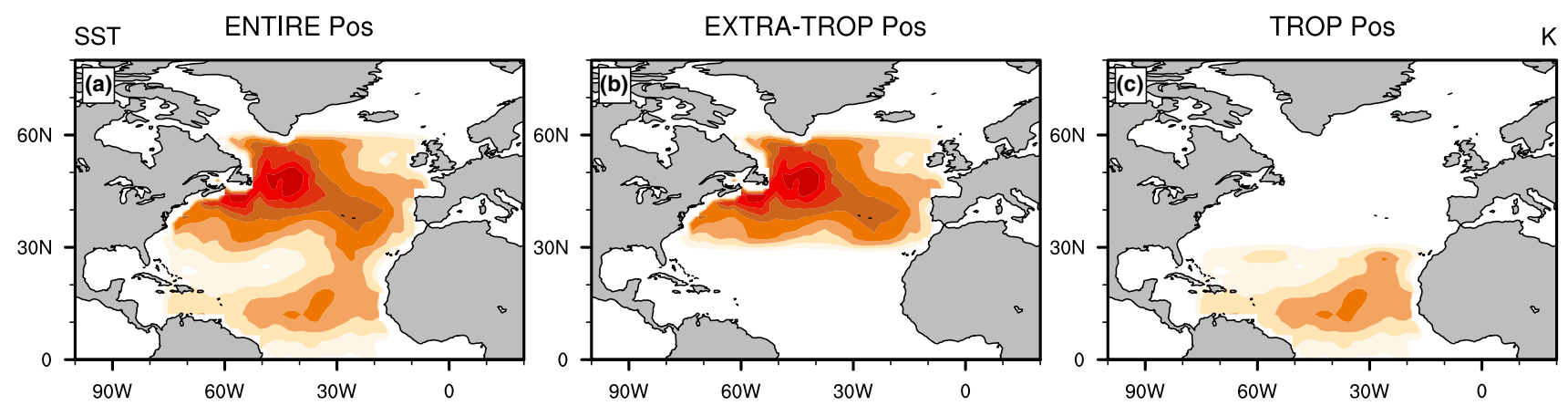

ENTIRE Neg

EXTRA-TROP Neg
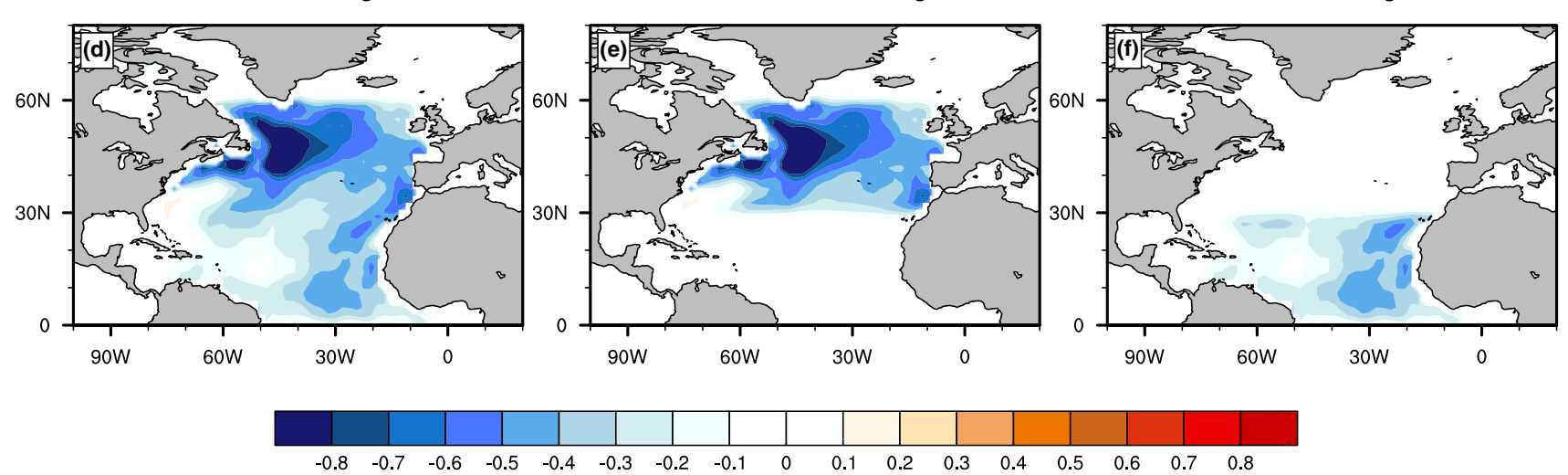

Fig. 1 AMV SST anomaly pattern averaged for the summer months (JJA) in positive phase for a entire North Atlantic, b extra-tropical North Atlantic, $\mathbf{c}$ tropical North Atlantic Ocean. d-f Are the same but for the negative phase. See Sect. 2 for the procedure to create the patterns. The units are in Kelvin $(\mathrm{K})$ 
regions further than $60^{\circ} \mathrm{N}$ by applying zero weighting. The AMV SST anomaly pattern is then multiplied by a factor of 2 to increase the signal to noise. To compare simulated fields with observations, model output is scaled by a factor of $1 / 2$, again. This procedure is in line with the previous studies, where the anomaly patterns are inflated from their observed values (Sutton and Hodson 2005, 2007). The averaged summer AMV SST anomaly pattern for the positive and negative phases are shown in Fig. 1a, d.

To understand which part of the AMV has a greater impact on the NAE climate, further experiments are conducted by adding the AMV pattern only over the extratropical North Atlantic $\left(30^{\circ} \mathrm{N}-60^{\circ} \mathrm{N}\right.$, EXTRA-TROP) and the tropical North Atlantic $\left(0^{\circ}-30^{\circ} \mathrm{N}\right.$, TROP), respectively. The respective AMV SST anomaly patterns used for the summer months over the EXTRA-TROP and TROP case for both positive and negative phases are shown in Fig. 1b, c, e and f. For continuity in the SST pattern, a smoothing is applied at the northern and southern edges of the added AMV pattern in all the experiments. The SSTs are smoothed by computing the weighted mean of each grid point at the edge (with weight 1.0) with its eight surrounding grid points, where the points above, below and aside are weighted 0.5 and the points at the corners are weighted 0.3. Each of these experiments is conducted for 50 model years where for each year, the same monthly AMV SST anomaly imposed global monthly climatological SST pattern is repeated. The essential details of these experiments are given in Table 1.

The atmospheric response of a quantity to the AMV SST anomaly is defined as the difference of the time-average of the quantity in an AMV forced experiment and the timeaverage of the quantity in the control experiment. Here the time average is solely performed for the summer months
(JJA). Further, we perform a Student's t-test on 95\% confidence level at each grid point to estimate the significance of the atmospheric response in the AMV forced experiment.

In our analysis, the Rossby wave response over the midlatitudes are confirmed by using the Rossby wave source (RWS) diagnostic following Sardeshmukh and Hoskins (1988). The RWS is derived from horizontal velocity $v$ using the following equation

$R W S=-\nabla \cdot\left(v_{\chi} \zeta\right)=-\left(\zeta \nabla \cdot v_{\chi}+v_{\chi} \cdot \nabla \zeta\right)$

where $\zeta$ denotes the absolute vorticity and $v_{\chi}$ is the divergent components of the horizontal wind $v$. The RWS peaks at around $200 \mathrm{hPa}$ and calculating the RWS from monthly rather than daily wind velocities makes no impact on the seasonal means (Scaife et al. 2017). Hence we derived the RWS from the monthly $200 \mathrm{hPa}$ wind velocities and further calculated the summer mean response.

The 20CRv2 has been used to evaluate the simulated atmospheric response from the positive and negative AMV forced experiments. In the 20CRv2, the time series of the first empirical orthogonal function (EOF) of the summer $2 \mathrm{~m}$ air temperature (11 year running mean) over the C-E European region $\left(35^{\circ} \mathrm{N}-75^{\circ} \mathrm{N}\right.$ and $\left.20^{\circ} \mathrm{W}-50^{\circ} \mathrm{E}\right)$ is defined as the C-E European SAT index in Ghosh et al. (2017). It is shown that the observed C-E European SAT index is very similar to the observed summer AMV index (Ghosh et al. 2017). Due to this close association, the composites are constructed using the C-E European SAT index are the same as the composites from the summer AMV index. Therefore to be consistent with the analysis shown from 20CRv2 in Ghosh et al. (2017), the AMV positive and negative phase composites in 20CRv2 have been constructed using the observed C-E European SAT index. The positive and negative AMV phase

Table 1 The details of the sensitivity experiments conducted using the atmospheric model ECHAM6.3

\begin{tabular}{llll}
\hline $\begin{array}{l}\text { Experi- } \\
\text { ment } \\
\text { no. }\end{array}$ & Experiment name & No. of years & Boundary forcing \\
\hline 1 & Control & 50 & $\begin{array}{l}\text { Seasonally varying global climatological SST and SIC (1979-2008) from HadISST } \\
\text { Same as control experiment plus two times observed monthly positive phase AMV SST anomalies } \\
\text { from } 0^{\circ} \text { to } 60^{\circ} \mathrm{N}\end{array}$ \\
3 & $\begin{array}{l}\text { ENTIRE Pos } \\
\text { ENTIRE Neg }\end{array}$ & 50 & $\begin{array}{l}\text { Same as control experiment plus two times observed monthly negative phase AMV SST anomalies } \\
\text { from } 0^{\circ} \text { to } 60^{\circ} \mathrm{N}\end{array}$ \\
4 & EXTRA-TROP Pos 50 & $\begin{array}{l}\text { Same as control experiment plus two times observed monthly positive phase AMV SST anomalies } \\
\text { from } 30^{\circ} \text { to } 60^{\circ} \mathrm{N}\end{array}$ \\
5 & EXTRA-TROP Neg & 50 & $\begin{array}{l}\text { Same as control experiment plus two times observed monthly negative phase AMV SST anomalies } \\
\text { from } 30^{\circ} \text { to } 60^{\circ} \mathrm{N}\end{array}$ \\
6 & TROP Pos & 50 & $\begin{array}{l}\text { Same as control experiment plus two times observed monthly positive phase AMV SST anomalies } \\
\text { from } 0^{\circ} \text { to } 30^{\circ} \mathrm{N}\end{array}$ \\
7 & TROP Neg & 50 & $\begin{array}{l}\text { Same as control experiment plus two times observed monthly negative phase AMV SST anomalies } \\
\text { from } 0^{\circ} \text { to } 30^{\circ} \mathrm{N}\end{array}$
\end{tabular}

The table mentions the names of the experiments, the duration of the simulation for each experiment and the specifics of the boundary forcings given to each experiment 
composites are defined as the average anomalous response of those years, when the observed C-E European SAT index is above and below the zero line, respectively.

\section{Results}

\subsection{Surface air temperature}

The SAT response in the 20CRv2, ENTIRE, EXTRA-TROP and TROP experiments for both positive and negative phases are shown in Fig. 2a-h. For the negative AMV phase, the
ENTIRE experiment shows negative SAT anomalies over the C-E European region (Fig. 2c). During this phase, the response is similar to what we expect from the observations (Fig. 2a). However, the model SAT responses seem to be weaker in amplitude than in observations. This is due to the fact that models in general simulate weaker atmospheric response from the SST anomalies than in the observations. The EXTRA-TROP experiment also displays similar negative SAT anomaly response over the C-E Europe with the same amplitude as in the ENTIRE experiment (Fig. 2d). Likewise the TROP experiment shows negative SAT anomaly response, which is however not significant (Fig. 2e).
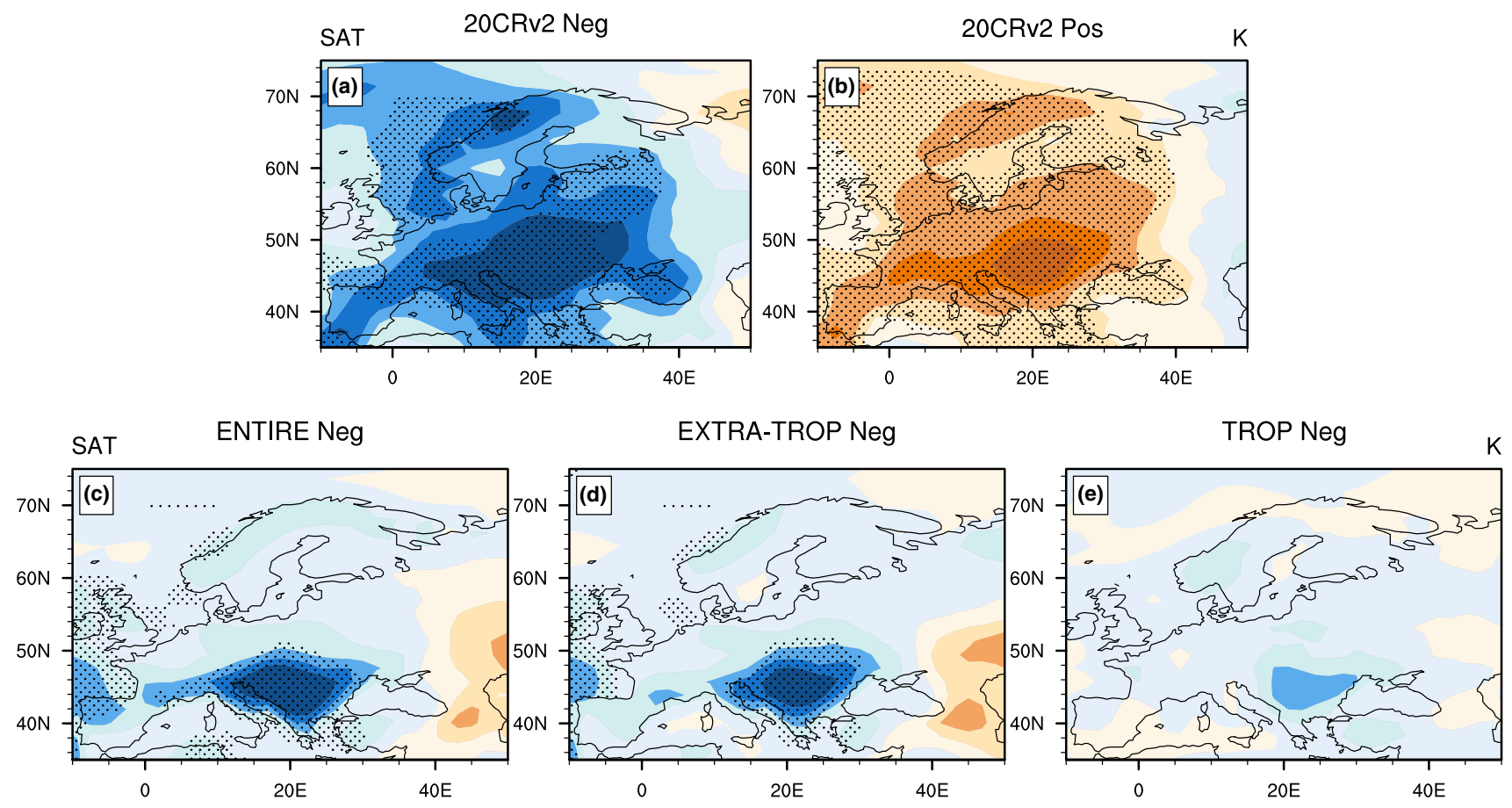

ENTIRE POS

EXTRA-TROP POS

TROP POS
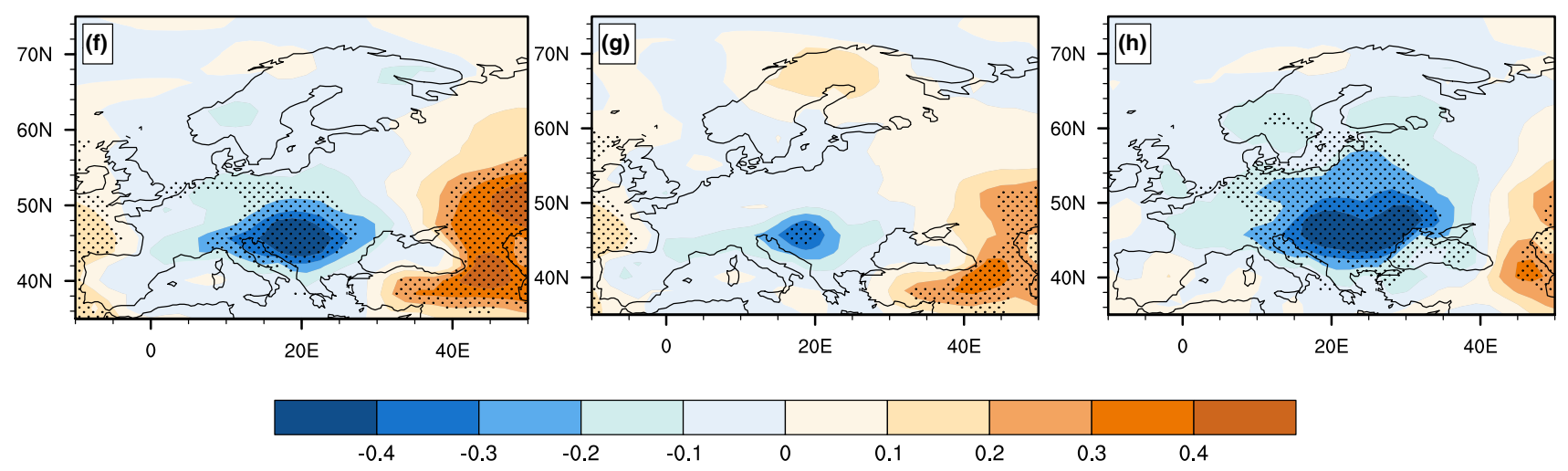

Fig. 2 The a negative and $\mathbf{b}$ positive phase composite of SAT with respect to the C-E European SAT index [black curve, Fig. $2 b$ in Ghosh et al. (2017)] from the 20CRv2. The SAT response from the AMV SST anomaly patterns shown in Fig. 1, averaged for the summer months (JJA) in negative phase for $\mathbf{c}$ entire North Atlantic, d extra-tropical North Atlantic, e tropical North Atlantic Ocean and $\mathbf{f}-\mathbf{h}$ are the same for the positive phase. The dotted regions denote areas with significance at the $95 \%$ confidence level. The units are in Kelvin (K) 
Hence in the negative AMV phase, the response over C-E Europe in the model resembles the observed response and it might be emerging from the extra-tropical branch of the AMV SST anomaly.

For the positive AMV phase of the ENTIRE experiment, the C-E European region displays negative SAT anomalies (Fig. 2f). This response is entirely opposite to what we have expected from the observational study in Ghosh et al. (2017) (Fig. 2b). In the TROP experiment, we find a similar strong negative SAT anomaly over the C-E European region (Fig. 2h). The EXTRA-TROP experiment also shows negative SAT anomaly response over C-E Europe (Fig. $2 \mathrm{~g}$ ). However, it is much smaller in amplitude than the response in the TROP experiment. These results imply that for the positive AMV phase, the response in the model over the C-E Europe is opposite to what is observed and the main contributor is the tropical branch of the AMV.

We now further investigate the atmospheric pathways for the negative and then the positive phase for all the experiments to identify the responses and understand the characteristics of the processes related to the response.

\subsection{Atmospheric pathway during the negative AMV phase}

\subsubsection{Sea level pressure}

The response in the negative phase composite with respect to C-E European SAT index derived from the 20CRv2 is shown in Fig. 3a. Further, the SLP responses in the ENTIRE,
EXTRA-TROP and TROP experiments for the negative AMV phase are shown in Fig. 3b-d. For the ENTIRE experiment, we find a significant presence of a surface high over the north-eastern Atlantic Ocean (Fig. 3b). In case of the EXTRA-TROP experiment, there is a significant and intense surface high pressure anomaly centered over the same location as in the ENTIRE experiment, which encompasses its influence over the NAE region (Fig. 3c). Moreover, the position and structure of this high is very similar to the high pressure anomaly in 20CRv2 negative phase response (Fig. 3a). Hence, the close resemblance of the high SLP anomaly in the EXTRA-TROP experiment with the negative AMV phase SLP response in 20CRv2 suggests that the model is able to simulate the observed response to extra-tropical AMV SST anomalies, the NEW mode, during the negative phase. On the contrary, in the TROP experiment there is a weak high pressure anomaly over the tropical region and no significant SLP anomalies are found over the extra-tropical Atlantic as well as over European region (Fig. 3d). This indicates that the response from the extratropical AMV SST anomalies is clearly playing the main role over the NAE region in the negative AMV phase of the model, supporting the observed mechanism in 20CRv2.

\subsubsection{Vertical structure of the geopotential height and temperature advection}

To confirm that the surface high in the negative AMV phase EXTRA-TROP experiment is indeed the observed NEW mode, we examine whether the vertical structure of the high
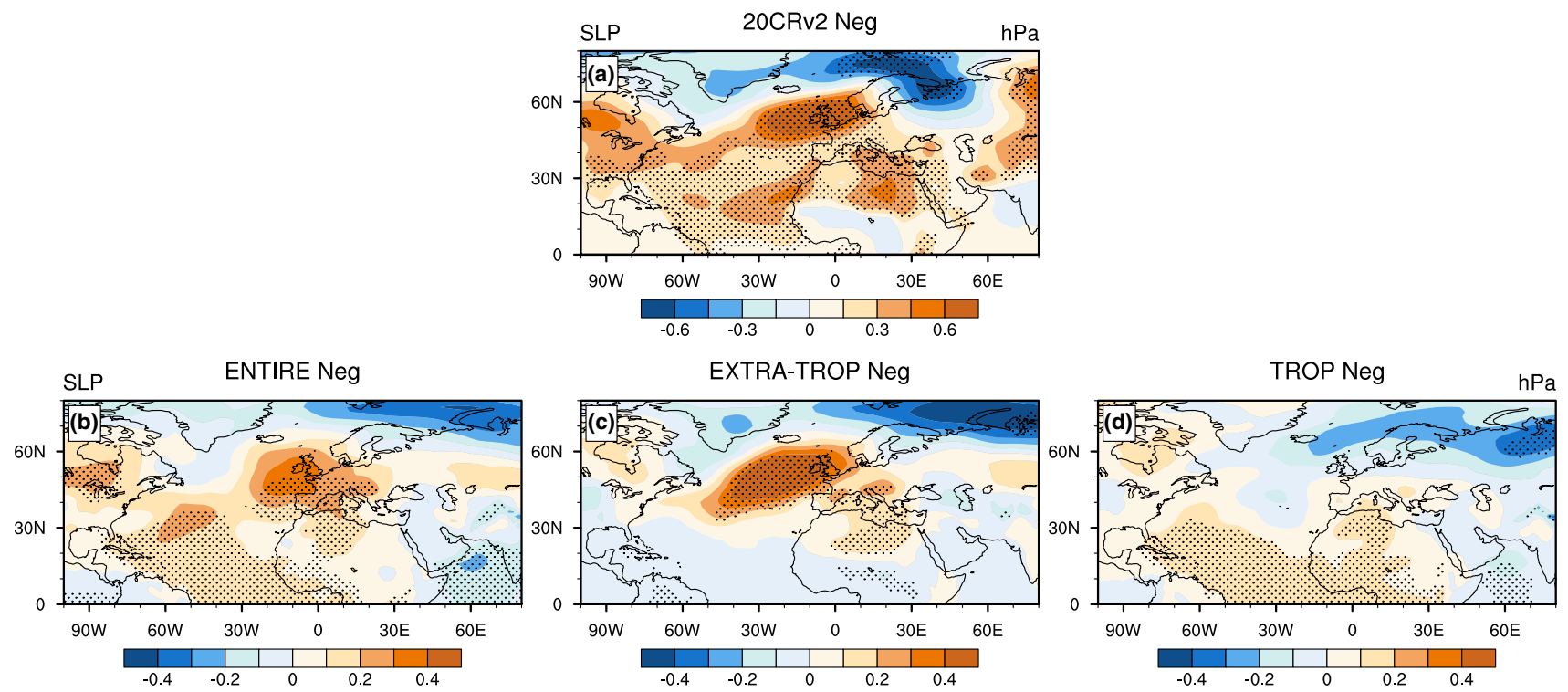

Fig. 3 a The negative phase composite of SLP with respect to the C-E European SAT index [black curve, Fig. 2b in Ghosh et al. (2017)] from the 20CRv2. The SLP response from the negative AMV SST anomaly patterns as shown in Fig. 1d-f averaged for the sum- mer months (JJA) for the b ENTIRE, $\mathbf{c}$ EXTRA-TROP and $\mathbf{d}$ TROP experiments. The dotted regions denote areas with significance at the $95 \%$ confidence level. The Figure a from 20CRv2 is having a different color scale than the others. The units are in $\mathrm{hPa}$ 
pressure anomaly has a baroclinic-like nature. The vertical structure of the geopotential height field is constructed by meridionally averaging over the latitude $30^{\circ} \mathrm{N}-60^{\circ} \mathrm{N}$. The response from the negative phase composite with respect to the C-E European SAT in 20CRv2 is shown in Fig. 4a. Additionally, the same geopotential height field for the negative AMV forced ENTIRE, EXTRA-TROP and TROP experiments are shown in Fig. 4b-d.

The response from the ENTIRE experiment shows a baroclinic nature of the positive surface geopotential height over the north-eastern Atlantic Ocean $\left(30^{\circ} \mathrm{W}-10^{\circ} \mathrm{E}\right)$, which is the west of Europe (Fig. 4b). Similarly, considering the significant region, the EXTRA-TROP experiment displays a baroclinic-like vertical structure of the surface high over the same region (Fig. 4c). Moreover, the vertical geopotential height structure of the ENTIRE experiment closely resembles the structure of the EXTRA-TROP experiment with two equivalent barotropic lows surrounding the baroclinic high. Therefore, it is apparent that under negative AMV forcing conditions the model atmospheric response over the NAE region is mainly contributed by the extra-tropical branch of the AMV. Further, the negative phase composite from the 20CRv2 shows a vertical structure similar to the structure in the ENTIRE as well as EXTRA-TROP experiments with the same baroclinic surface high surrounded by two barotropic lows (Fig. 4a). From the TROP experiment it is evident that the tropical negative AMV SST anomaly forcing has no significant effect over the extra-tropical region in the negative AMV phase (Fig. 4d). Hence, it implies that the model response to the extra-tropical negative AMV forcing can closely replicate the overall nature of the observed response in the negative AMV phase over the NAE region and also the model can simulate the observed baroclinic like nature of the positive surface height anomalies over the north-eastern Atlantic Ocean from the negative extratropical SST anomalies.

According to the linear quasi-geostrophic theory, a baroclinic response from the mid-latitude diabatic heating can further be confirmed, if the heating is balanced by horizontal temperature advection under the quasi-geostophic approximation (Hoskins and Karoly 1981; Kushnir et al. 2002). Hence, to confirm the baroclinic nature and the similarities in the response from the negative AMV phase EXTRA-TROP experiment and in the 20CRv2, Fig. 5 shows the meridional temperature advection $\left(-v^{\prime} \frac{\partial \bar{\theta}}{\partial y}\right)$ response, which is the dominant horizontal advection term in the thermodynamic energy equation (Ghosh et al. 2017). The $v^{\prime}$ is the deviation of the meridional velocity from the zonal mean and $\frac{\partial \bar{\theta}}{\partial y}$ is the meridional

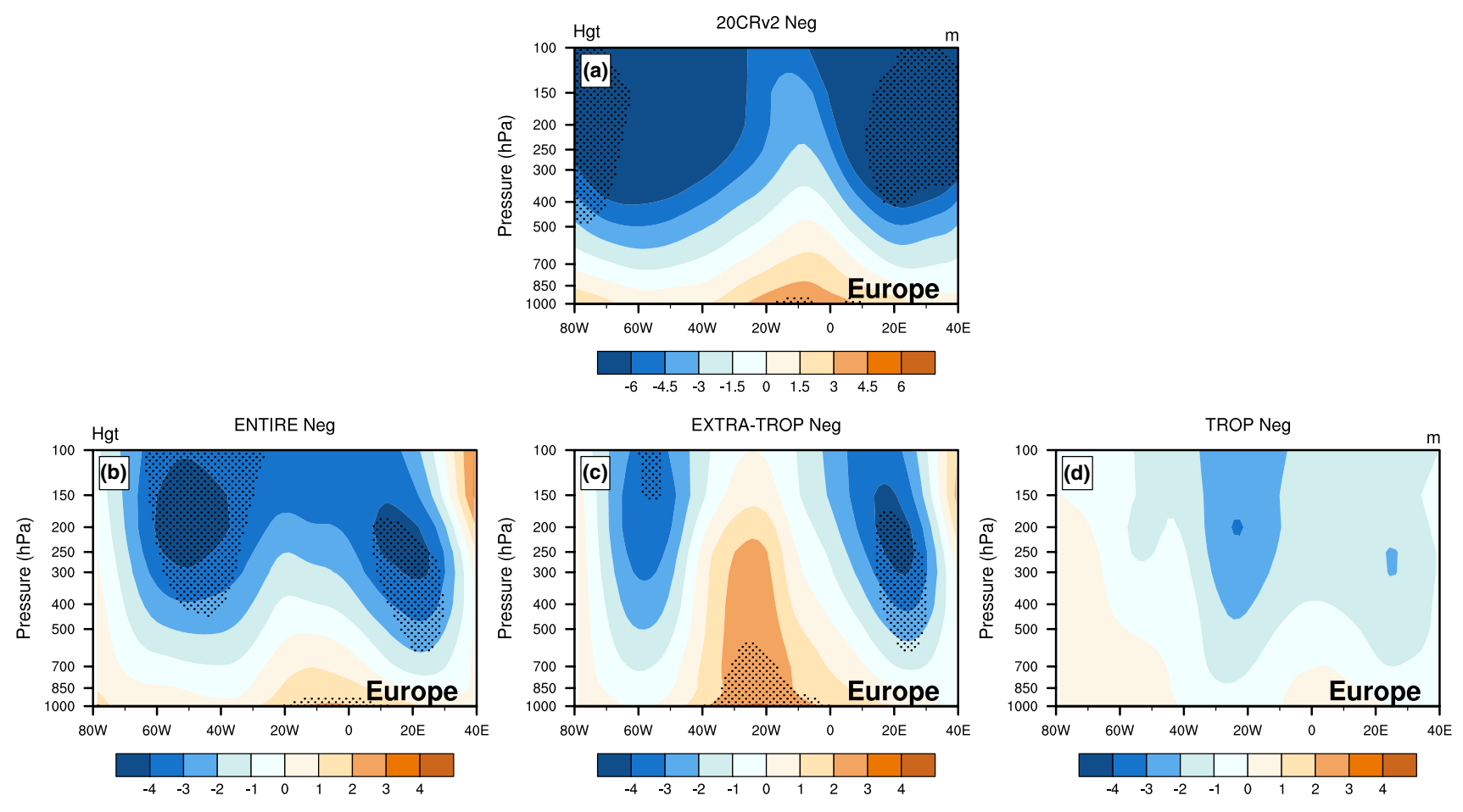

Fig. 4 The vertical structure of the geopotential height response meridionally averaged over the latitude $30^{\circ}-60^{\circ} \mathrm{N}$ for a the negative phase composite with respect to the C-E European SAT index [black curve, Fig. 2b in Ghosh et al. (2017)] from the 20CRv2 and from the negative AMV SST anomaly patterns as shown in Fig. 1d-f in the summer period (JJA) for the b ENTIRE c EXTRA-TROP d TROP experiments. The European region is indicated by the text Europe. The dotted regions denote areas with significance at the $95 \%$ confidence level. The Figure a from 20CRv2 is having a different color scale than the others. Units are in meter (m) 

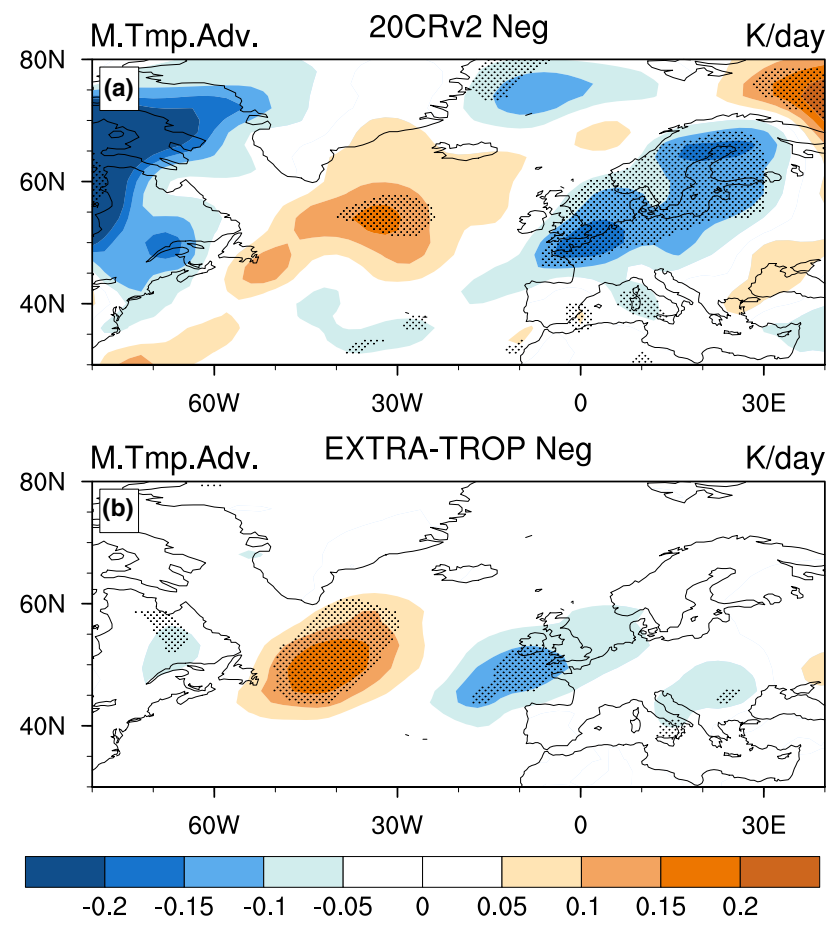

Fig. 5 The response of the meridional temperature advection $-v^{\prime} \frac{\partial \bar{\theta}}{\partial y}$ at $850 \mathrm{hPa}$, after Hoskins and Karoly (1981), where $v^{\prime}$ is the deviation of the meridional velocity from zonal mean, and $\bar{\theta}$ is the zonal mean potential temperature a in the negative phase composite with respect to the C-E European SAT index [black curve, Fig. $2 b$ in Ghosh et al. (2017)] from the 20CRv2 and $\mathbf{b}$ in the EXTRA-TROP experiment with the negative AMV. The dotted regions denote areas with significance at the $95 \%$ confidence level. Units are in Kelvin per day (K/ day)

gradient of the zonal mean potential temperature $\bar{\theta}$. The positive values denote the advection is north-ward and the negative values denote that the advection is south-ward. The response in the EXTRA-TROP experiment shows cold air advection over the European region and warm air advection over the negative SST anomalies in the northwestern Atlantic Ocean (Fig. 5b). This temperature advection pattern follows the surface high that we see in the SLP response over the NAE region (Fig. 3b). The temperature advection response over the NAE region in the $20 \mathrm{CRv} 2$ for the negative phase composite is very similar to the response seen in the experiment, with cold air advection over the Europe and warmer air advection over the north-west Atlantic Ocean (Fig. 5a). This close resemblance strongly suggests that the model generated response in the negative AMV phase EXTRA-TROP experiment is following a linear quasi-geostrophic response to the midlatitude cooling, as elaborated in Ghosh et al. (2017).

\subsubsection{Response from the tropical part of the AMV}

The analysis of the SAT, SLP and geopotential height in the negative AMV phase of the model experiments have shown that the tropical part of the AMV SST anomaly is not affecting the European summer climate. Previous studies have mentioned that the tropical SST anomalies lead to linear response in associated precipitation anomalies and eventually in tropical circulation anomalies (Gill 1980; Sutton and Hodson 2007). The changes in the circulations affect the tropical part of the North and South American continent (Sutton and Hodson 2007; Hodson et al. 2010). In our experiments, we indeed find the similar linear response from the tropical AMV SST anomalies. The negative AMV SST anomalies lead to negative precipitation anomalies and upper level convergence over the tropics (Fig. 6a, b). The response is very linear when compared with the response from the positive tropical AMV SST anomalies (Fig. 10c, f). Nevertheless, the response from the tropical AMV SST anomalies to extra-tropics is not linear. The tropics can affect the extra-tropics through poleward propagating stationary Rossby waves. The RWS response in Fig. $6 \mathrm{c}$ from the TROP negative AMV experiment shows no clear Rossby wave propagation over the midlatitude. Whereas in the TROP positive AMV experiment, we can see a prominent Rossby wave propagation signature over the midlatitude and especially over Eurasian continent (Fig. 11c). It could be the reason why in our model experiments we do not see any influence on the C-E European SAT from the tropical AMV SST anomalies in the negative phase compared to the positive phase (Fig. 2e, h).

Irrespective of the model responses from the tropical part of the AMV SST, we should keep in mind that the SST is non-interactive in our experimental setup. There is growing evidence that the tropical part of the AMV SST is atmosphere driven (Brown et al. 2016; Yuan et al. 2016; Drews and Greatbatch 2016, 2017). In that case, the response from the tropical part of the AMV, which anyways fails to reproduce the observed response, is merely an outcome of the experimentalsetup. Moreover, we can see that this spurious response from the tropical AMV SST also affects the quality of the well simulated desired response from the extra-tropical AMV SST in the ENTIRE experiment (Fig. 3). 
Fig. 6 The a precipitation $\mathbf{b}$ velocity potential at $200 \mathrm{hPa}$ and $\mathbf{c}$ Rossby Wave Source (RWS) response in the TROP experiment with the negative AMV SST anomaly pattern as shown in Fig. 1f averaged for the summer months (JJA). The units are in $\mathrm{mm} /$ day for the precipitation, $10^{5} \mathrm{~m}^{2} \mathrm{~s}^{-1}$ for the velocity potential and $10^{-11} \mathrm{~s}^{-2}$ for the RWS. The dotted regions denote areas with significance at the $95 \%$ confidence level
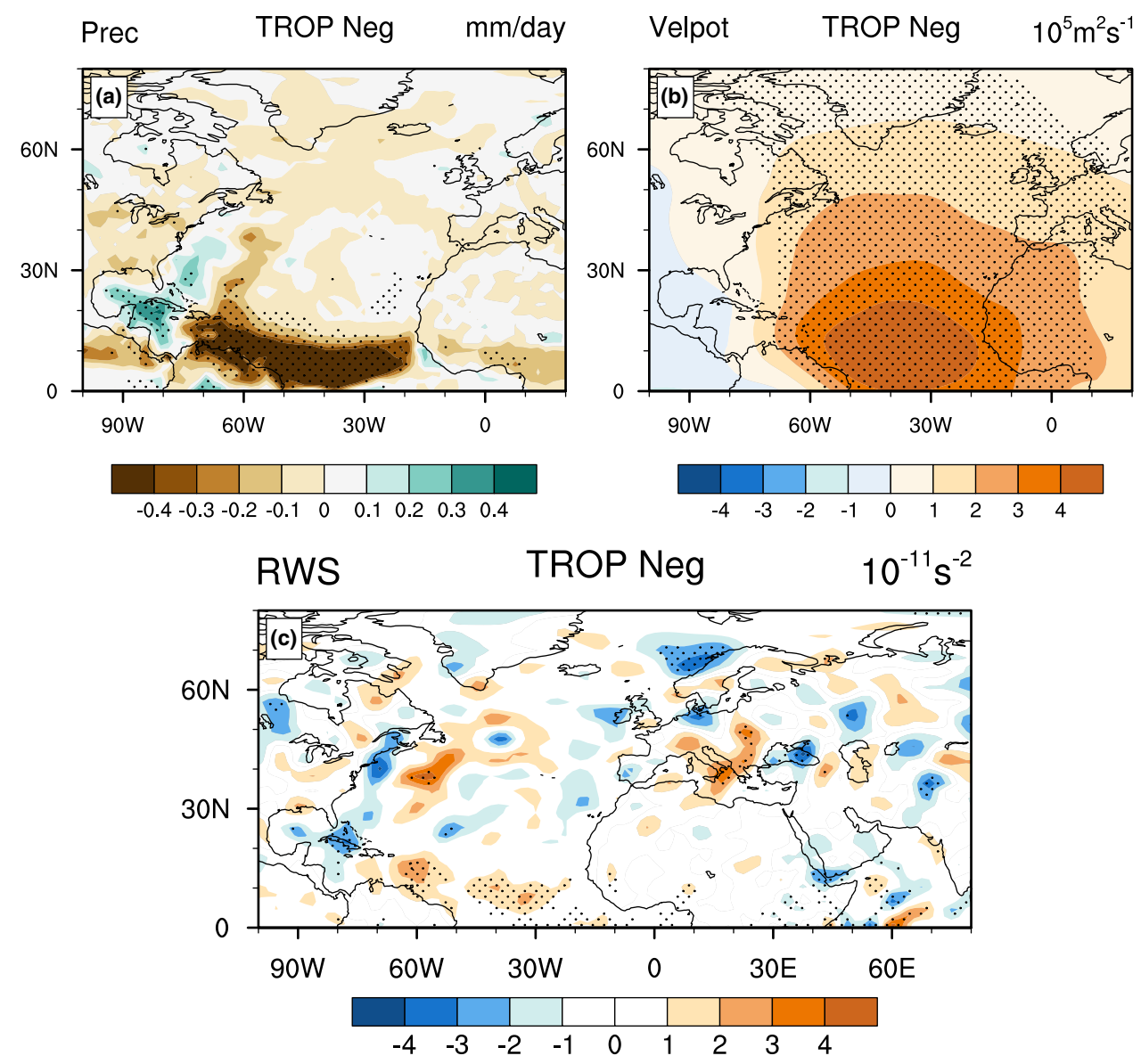

\subsection{Atmospheric pathways during the positive AMV phase}

\subsubsection{Sea level pressure and vertical structure of the geopotential height}

The response in the positive phase composite with respect to the C-E European SAT index from the 20CRv2 is shown in Fig. 7a. Further, the SLP response in the ENTIRE, EXTRATROP and TROP experiments for the positive AMV phase are shown in Fig. 7b-d.

It is apparent that for all of the model experiments, the SLP response to positive AMV SST anomalies has no resemblance to the SLP response in the 20CRv2 over the NAE region. The clear presence of the intense surface low pressure anomaly over the west coast of the European continent and the associated wave train, the observed NEW response, is missing in the experiments. The inability to simulate the NEW response leads to the failure to simulate the observed SAT response over the C-E Europe (Fig. 2). Moreover, over the tropical part, the responses in the TROP and ENTIRE experiments show a surface low over the western tropical Atlantic Ocean. However, in the 20CRv2, the surface low is over the eastern tropical Atlantic Ocean. This suggests a western tropical Atlantic forcing in the sensitivity experiments during the positive AMV phase, which we do not find in the reanalysis.

For the ENTIRE experiment, the SLP response displays a negative SLP anomaly over the western to central North Atlantic region (Fig. 7b). In the case of the extra-tropical AMV, there is a negative SLP anomaly pattern located over the western North Atlantic Ocean at around $40^{\circ} \mathrm{N}$ (Fig. 7c). Figure 1d shows strong positive SST anomalies just below the negative SLP anomalies, hence, indicating convection from localized heating over this region (Fig. 10b). The SLP response in the TROP experiment shows a negative SLP anomalies over the Caribbean region, similar to the ENTIRE experiment (Fig. 7d). Further, the SLP response consists of surface high pressure north-east of the low, which however is not significant. The surface high is followed by a surface low pressure anomaly downstream. The pattern resembles the SLP signature of a stationary Rossby wave emanating from the tropics due to positive tropical SST anomalies and associated positive precipitation anomalies (Terray and Cassou 2002; Wulff et al. 2017). This aspect is further explored in the next section. The SLP pattern over the NAE region however has similarities with both the tropical and extra-tropical AMV forced experiments. This indicates that 

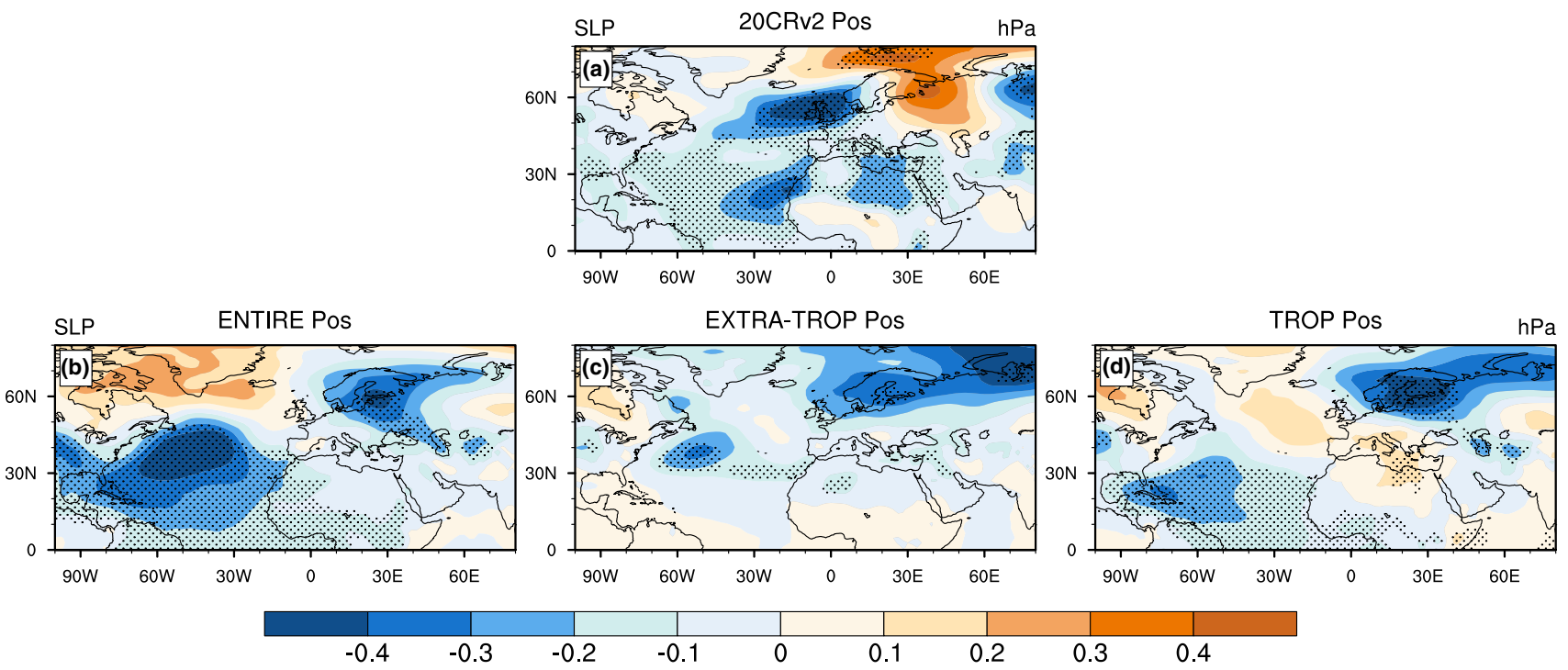

Fig. 7 a The positive phase composite with respect to the C-E European SAT index [black curve, Fig. 2b in Ghosh et al. (2017)] from the 20CRv2. The SLP response from the positive AMV SST anomaly patterns as shown in Fig. 1a-c averaged for the summer months (JJA) in the b ENTIRE, c EXTRA-TROP and d TROP experiments. The dotted regions denote areas with significance at the $95 \%$ confidence level. The units are in $\mathrm{hPa}$

indicates a barotropic nature of the response over the extratropics, similar to the stationary Rossby waves (Terray and Cassou 2002). Apparently, this wave-like response creates a favorable situation to advect the colder winds from the higher latitudes to the C-E European region. The response in height fields at $500 \mathrm{hPa}$ for the TROP experiment shows a very similar atmospheric pattern over the NAE region, especially over Eurasia, indicating a dominant contribution from the tropical branch of the AMV through stationary Rossby wave generation (Fig. 8c). The extra-tropical AMV response also displays almost similar atmospheric pattern over the mid-latitude, where the surface low over the south of Newfoundland is diminished in the upper levels and the downstream high pressure is strengthened (Fig. 8b). Nevertheless, the low pressure response over the European region, which plays a crucial role to bring colder winds to C-E Europe,
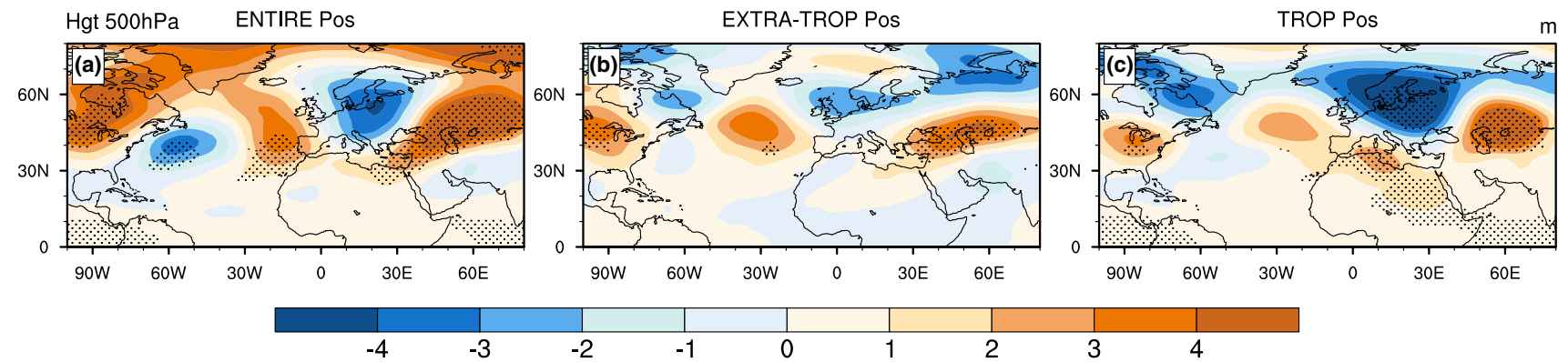

Fig. 8 The geopotential height at $500 \mathrm{hPa}$ response from the positive AMV SST anomaly patterns as shown in Fig. 1a-c, averaged for the summer months (JJA) in the a ENTIRE, b EXTRA-TROP and c
TROP experiments. The dotted regions denote areas with significance at $95 \%$ confidence level. The units are in meters (m) 
is much weaker than in the ENTIRE experiment and not significant compared to the TROP experiment. These results further assures that the response over the $\mathrm{C}-\mathrm{E}$ Europe during the positive AMV phase in the model, is mainly due to the tropical branch of AMV through stationary Rossby waves.

In the positive AMV phase experiments, the barotropic and baroclinic natures of the responses over the midlatitudes are shown through the vertical structure of the geopotential height fields averaged over the latitude $30^{\circ} \mathrm{N}-60^{\circ} \mathrm{N}$ (Fig. 9). Over the North Atlantic Ocean $\left(80^{\circ} \mathrm{W}-0^{\circ} \mathrm{W} / \mathrm{E}\right)$, the response in the ENTIRE experiment is having a baroclinic low $\left(45^{\circ} \mathrm{W}\right.$ and westward) and an equivalent barotropic high east of the low (Fig. 9a-c). A similarly strong and significant high at the upper levels can be seen in the EXTRA-TROP experiment.
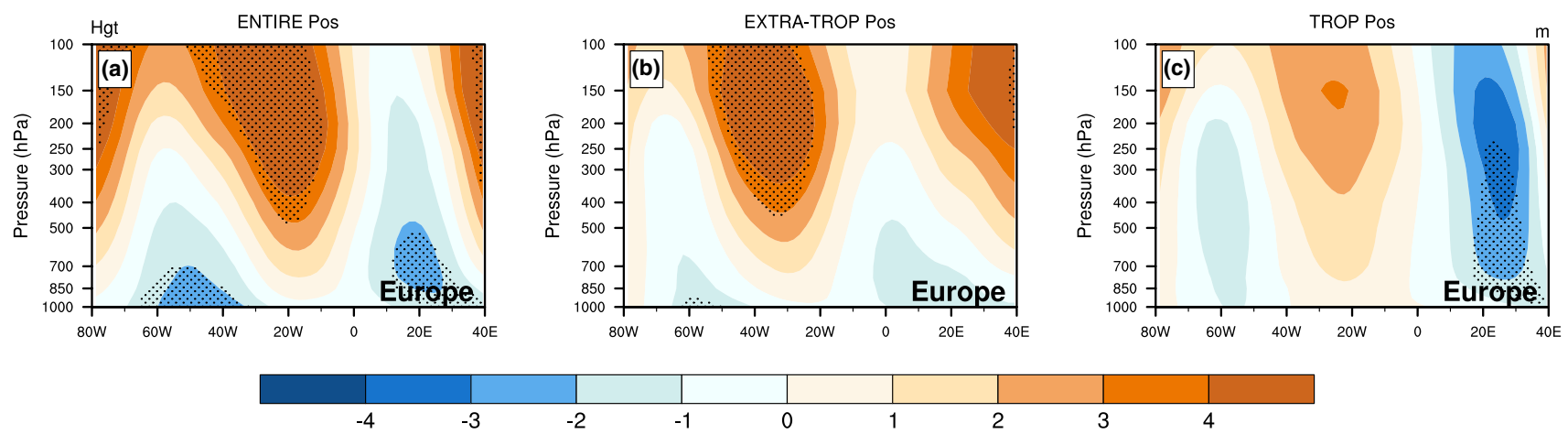

Fig. 9 The vertical structure of the geopotential height response, meridionally averaged over the latitude $30^{\circ}-60^{\circ} \mathrm{N}$, from the positive AMV SST anomaly patterns shown in Fig. 1a-c in the summer period (JJA) for the a ENTIRE b EXTRA-TROP c TROP experi- ments. The European region is indicated by the text Europe. The dotted regions denote areas with significance at the $95 \%$ confidence level. The units are in meters $(\mathrm{m})$
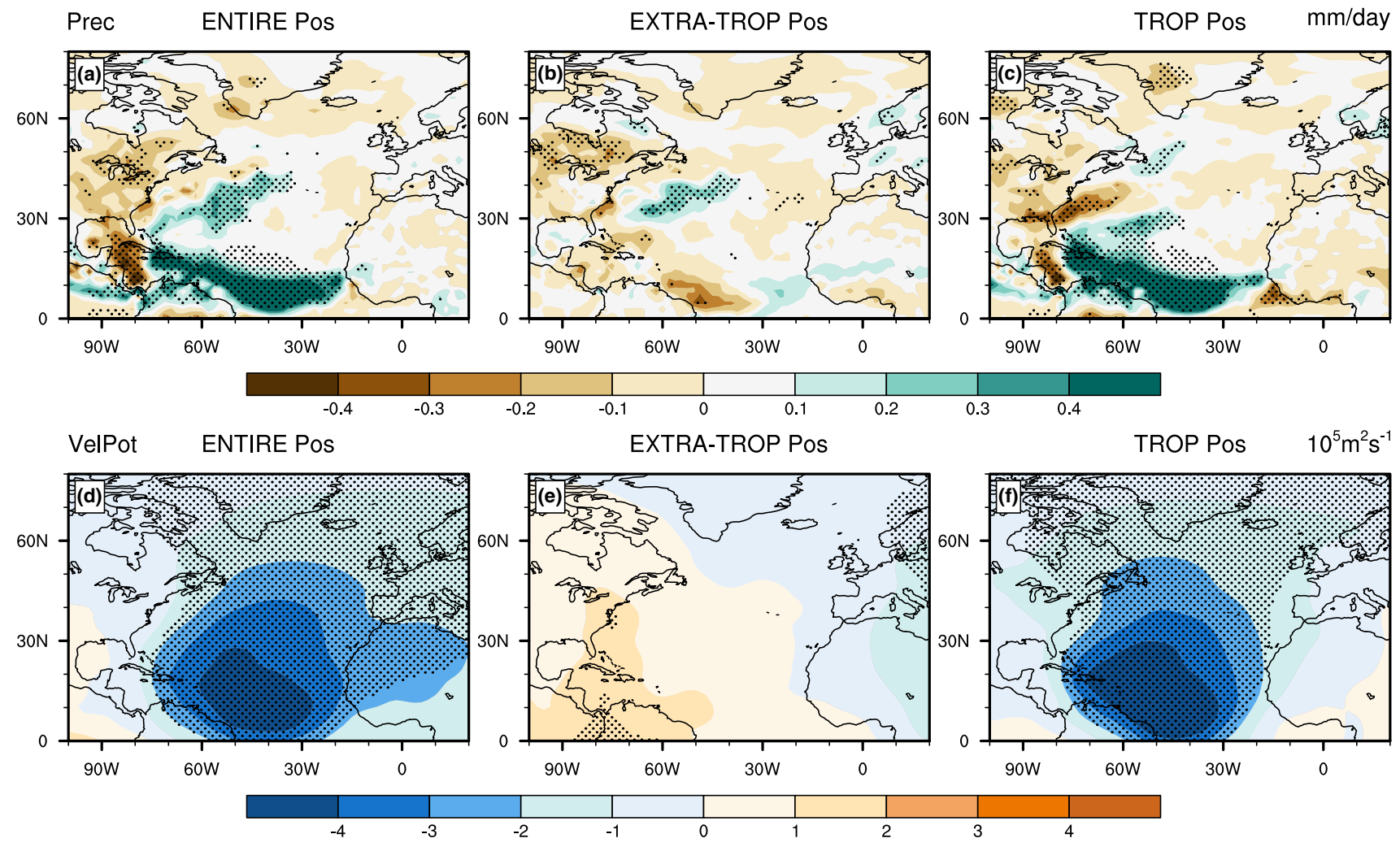

Fig. 10 The precipitation response from the positive AMV SST anomaly patterns as shown in Fig. 1a-c averaged for the summer months (JJA) for the a ENTIRE, b EXTRA-TROP and c TROP experiments. The units are in $\mathrm{mm} /$ day. $\mathbf{d}-\mathbf{f}$ Are same as a-c but for $200 \mathrm{hPa}$ velocity potential. Units are in $10^{5} \mathrm{~m}^{2} \mathrm{~s}^{-1}$. The dotted regions denote areas with significance at the $95 \%$ confidence level 
However, the response over the North Atlantic Ocean in the ENTIRE experiment appears to be stronger than TROP and EXTRA-TROP experiments alone and it is almost the combination of the responses from these two experiments. Whereas proceeding towards the east, the response over the European region $\left(0^{\circ} \mathrm{E}-40^{\circ} \mathrm{E}\right)$ shows a significant low pressure anomaly with a barotropic structure only in the ENTIRE and TROP experiments. This again indicates that during the positive phase, the model response over the European region is mainly influenced by the tropical AMV.

\subsubsection{Tropical AMV influence}

The dominant role of the tropical branch of the AMV in the positive phase of the model experiments is briefly shown through the precipitation and $200 \mathrm{hPa}$ velocity potential responses for the ENTIRE, EXTRA-TROP and TROP experiments in Fig. 10. Typically, the tropical offequatorial heating produces a Gill-type response, which can be detected through high positive precipitation anomalies and strong upper level divergence of the wind (Sutton and Hodson 2007; Hodson et al. 2010). The upper level divergent wind then leads to the stationary Rossby waves, through the convergence of the wind away from the equator and/or through the interaction of the divergent flow with the jet stream, which then propagates pole-ward and east-ward (Hoskins and Karoly 1981; Sardeshmukh and Hoskins 1988). In both the ENTIRE and TROP experiments, there are intense positive precipitation anomalies over the tropical Atlantic region (Fig. 10a, c). Further, the $200 \mathrm{hPa}$ velocity potential field shows intense negative anomalies, indicating strong divergence of the wind at the upper levels over the anomalous precipitation region in the tropics (Fig. 10d, f). This confirms the presence of the Gill-type response from the tropics in the TROP, as well as the ENTIRE experiment. There is no sign of such response in the EXTRA-TROP experiment (Fig. 10b, e). However, in case of the precipitation anomalies for the EXTRA-TROP experiment (Fig. 10b), there is a significant positive precipitation anomaly associated with the surface low over the North Atlantic ocean (Fig. 7c). This supports the hypothesis of a convective response from localized heating, associated with the extra-tropical AMV SST anomalies. However, the point to note is that a similar response can not be seen in the 20CRv2 (Fig. 7a). Therefore, the surface low and associated precipitation anomalies in the EXTRA-TROP experiment of the model are most certainly a model artifact and a consequence of prescribing the SST in an AGCM (Hand et al. 2014).

The stationary Rossby wave propagation from the tropical Atlantic positive precipitation anomalies can be confirmed from the analysis of the Rossby wave source (RWS) following Sardeshmukh and Hoskins (1988). Figure 11 shows the summer RWS anomalies in the positive AMV forced ENTIRE, EXTRA-TROP and TROP experiments compared to the control run. Both in ENTIRE and TROP experiments, where we have seen intense positive precipitation anomalies, an intense Rossby wave activity can be seen with a tropical Atlantic origin (Fig. 11a, c). They both are in agreement with the height anomalies, where the positive vorticity source is upstream of the negative height anomalies and vice-verse (Fig. 8). Compared to these two experiments, the EXTRA-TROP experiment shows much weaker RWS anomalies over the extra-tropics, indicating the Rossby wave like response in the ENTIRE experiment is coming from the tropical part of the positive AMV SST anomalies.

However, we must not forget that in our experimental setup the SST is not interactive, while there is a growing consensus that the tropical part of the AMV is atmosphere forced (Brown et al. 2016; Yuan et al. 2016; Drews and Greatbatch 2016, 2017). We have also seen in our analysis that the response from the tropical AMV SST has no similarity with the response from the 20CRv2 (Fig. 7). Therefore, the tropical AMV SST response might entirely be due to the experimental constraint.

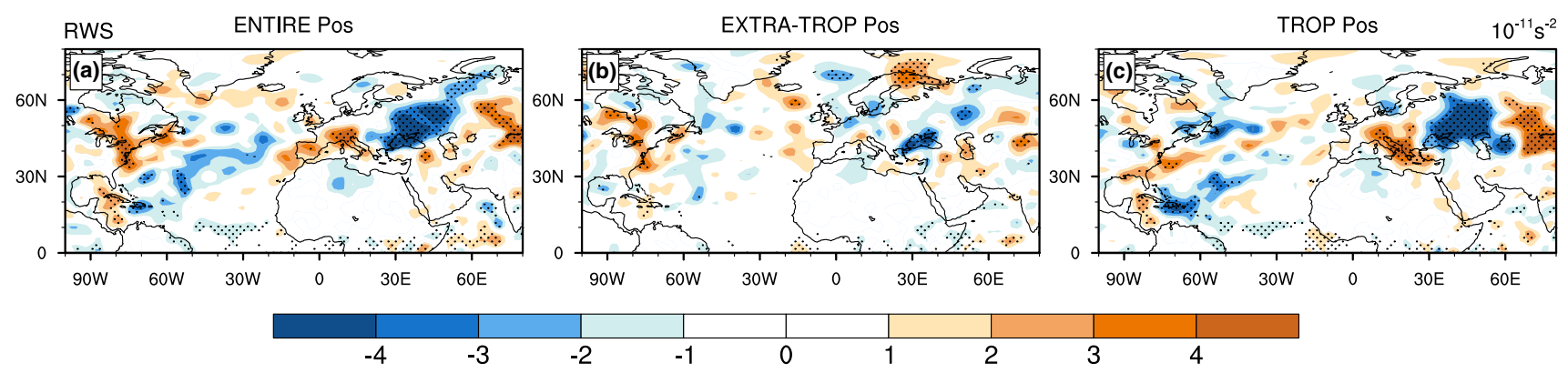

Fig. 11 The Rossby Wave Source (RWS) response from the positive AMV SST anomaly patterns as shown in Fig. 1a-c, averaged for the summer months (JJA) in the a ENTIRE, b EXTRA-TROP and $\mathbf{c}$ TROP experiments. Red colors indicates positive (cyclonic) and blue (anticyclonic) color indicates negative sources of vorticity. The dotted regions denote areas with significance at $95 \%$ confidence level. The units are in $10^{-11} \mathrm{~s}^{-2}$ 


\section{Discussion}

The results from the sensitivity experiments show that during the negative AMV phase, the model is able to simulate the observed linear baroclinic response from the extratropical SST anomalies. However, in the positive AMV phase, the response from the extra-tropical AMV SST anomalies does not resemble the linear baroclinic response from midlatitude heating as found in 20CRv2. Hence, we do not find the similar observed SAT response over C-E Europe from the positive AMV SST anomalies in the sensitivity experiments. One of the reasons for this could be the differences in the turbulent heat flux associated with the SST anomalies in the model compared to 20CRv2. The turbulent (sensible + latent) heat flux response over the midlatitudes is shown for the positive AMV phase ENTIRE, EXTRA-TROP experiments and for the positive phase composite with respect to the C-E European SAT index from 20CRv2 in Fig. 12.

There is a distinct difference in the heat flux response over the north-western Atlantic Ocean in the experiments (Fig. 12a, b) in comparison to the 20CRv2 (Fig. 12c). In both the EXTRA-TROP and ENTIRE experiments, the most intense heat flux anomalies are in the south of Newfoundland around $40^{\circ} \mathrm{N}$. Moreover, the low pressure anomaly response and the positive precipitation anomaly response coincide with the region of the intense positive heat flux anomalies in these experiments. This indicates that, the EXTRA-TROP response in the positive AMV case is originating from this diabatic heating region. However, in the 20CRv2 the most intense positive heat flux anomalies are further north-eastward, east of the Newfoundland, around $50^{\circ} \mathrm{N}$. It could be possible that due to the model deficiency to simulate the exact location of the observed diabatic heating region, the model is not able to simulate the observed SLP response from the heat flux anomalies. Instead, the model tends to create a convective response from the localized heating in the south of Newfoundland at around $40^{\circ} \mathrm{N}$.

It is also worth mentioning that we compare here the reanalysis with the prescribed SST experiments. Using sensitivity experiments with prescribed SST anomaly patterns are a common and appropriate method to study the atmospheric response to specific ocean modes. However, a crucial difference to observations/reanalysis is, that the feedbacks from the atmosphere to the ocean can not be reproduced in prescribed-SST setup. The previous studies have provided mounting evidence that the atmosphere could drive the tropical part of the AMV (Brown et al. 2016; Yuan et al. 2016; Drews and Greatbatch 2016, 2017). In particular, the cloud feedback plays an important role to modulate the SST anomalies (Brown et al. 2016). In our study, the major differences from the reanalysis are indeed found due the tropical part of the AMV. Hence the lack of atmosphere-ocean feedback might have also an influence behind the differences in the atmospheric responses in the reanalysis and in the experiments.

On the other hand, apart from AMV, the effect of the oceanic forcing from the tropics on the European climate need not be an atmospheric model artifact under prescribed SST. A previous study has shown by comparing reanalysis and the model results, that the tropical SST anomalies can influence the European summer climate by generating Rossby waves (Wulff et al. 2017). In their study, the observed Summer East Atlantic Pattern is suggested to be generated by the tropical Pacific positive SST and associated precipitation anomalies. In our study, a similar Rossby wave response has been shown from the tropical Atlantic positive SST anomalies. Due to the difference in the location of triggering SST and precipitation anomalies, both Rossby wave patterns are not in phase over the extra-tropics.

To partly incorporate the atmosphere-ocean feedback, a similar set of experiments have been performed to understand the impact of AMV, but with coupled models, where the SST is restored to AMV over the North Atlantic and
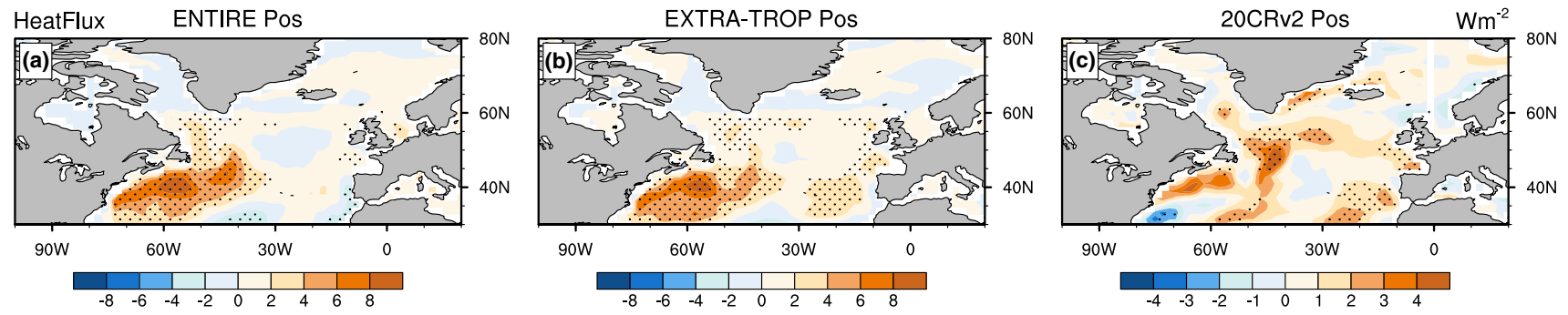

Fig. 12 The sensible + latent heat flux response from the positive AMV SST anomaly patterns as shown in Fig. 1a-c, averaged for the summer months (JJA) for the a ENTIRE, b EXTRA-TROP experiments and $\mathbf{c}$ for the positive phase composite with respect to the $\mathrm{C}-\mathrm{E}$ European SAT index [black curve, Fig. 2b in Ghosh et al. (2017)] from the 20CRv2. Positive values denote that the flux is from the ocean to the atmosphere. The dotted regions denote areas with significance at the $95 \%$ confidence level. The Figure $\mathbf{c}$ from 20CRv2 is having a different color scale than the others. Units are in $\mathrm{W} \mathrm{m}^{-2}$ 
elsewhere the ocean is free to interact with atmosphere and ocean circulations (Ruprich-Robert et al. 2017). Their study could show summer warming over the Eurasian continent with the positive phase of AMV. However, the cause or origin of the warming and its comparison with the observed responses are not shown in this study. Given the considerable climatological SST biases in the coupled models, especially over extra-tropical North Atlantic (Jungclaus et al. 2013; Wang et al. 2014), a similar SST restoring experimental setup could be helpful to understand the summer response of AMV on Europe in the coupled models.

The non-linearity in the atmospheric response over the extra-tropical region between the positive and negative AMV phase experiments could be due to the non-linearity in the AMV forcing itself. The sum of the SST conditions between the positive AMV forcing and the negative AMV forcing is shown in Fig. 13. It clearly shows that the positive and negative AMV forcing is not entirely linear. The positive values denote the regions where the positive AMV forcing is stronger and the negative values denote the opposite. The positive AMV forcing is stronger over the western tropical Atlantic Ocean and the east coast of North America. This region is more sensitive to generate the stationary Rossby wave response (Terray and Cassou 2002) which we indeed find in the positive AMV experiments (Fig. 11). Whereas the negative AMV forcing is stronger over the north-western, eastern Atlantic Ocean and over the eastern tropical Atlantic Ocean. The strength of SST anomalies over the north-western Atlantic Ocean, east of Newfoundland, is the main region for generating linear baroclinic response from midlatitude heating. Therefore, this indicates that the

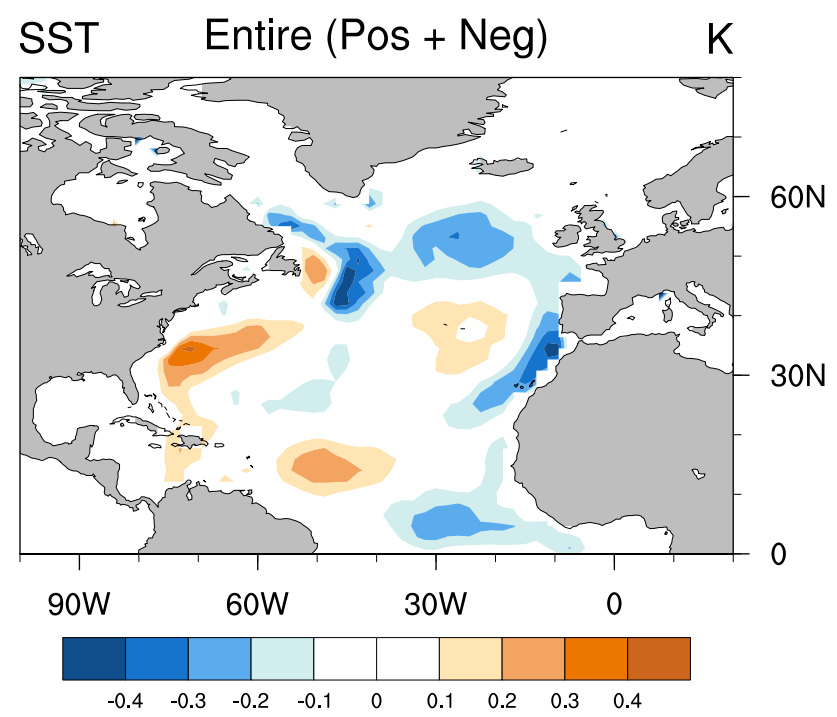

Fig. 13 The sum of the SST pattern over the Atlantic Ocean in summer (JJA) between the positive AMV ENTIRE experiment and the negative AMV ENTIRE experiment (SST anomaly pattern of Fig. 1a $+\mathrm{d})$. Units are in Kelvin (K) magnitude of SST anomalies over the north-western Atlantic Ocean is stronger in the negative AMV phase than in the positive AMV phase and, hence, we have been able to see the observed NEW response in negative AMV phase of the model. It would be interesting to see if the model is able to simulate the observed NEW response in the positive phase, when the negative AMV forcing is applied after changing its phase by multiplying with -1 . This will make the forcing stronger over the desired location and also will enable us to understand the response with the linear forcing. However, as described earlier, the lack of interactive SST might still limit our ability to simulate the observed response.

It is also worth mentioning that a low resolution version of the model (approximately $2^{\circ}$ grid) is used for our experiments and we could capture the observed response on the European climate in the negative AMV phase. Increasing the resolution could provide us with an improved climate state, which might lead to further improvements in the responses simulated by the model.

As a matter of fact, the findings of this study is based on a single model analysis. To understand the robustness of the results in different model frameworks, it is essential to conduct further a multimodel analysis of the observed AMV impact on European summer climate.

\section{Conclusions}

The results from the AMIP type sensitivity experiments with the negative and positive AMV forcing can be summarized as follows:

- In the negative AMV forced experiment, the SAT response over C-E Europe shows negative anomalies, similar to the observed anomalies for decadal mean SATs in the negative AMV phase, as found in Ghosh et al. (2017).

- The SAT response over C-E Europe in the negative phase is due to the extra-tropical branch of the AMV, in association with a baroclinic response from the extra-tropical SST anomalies. The SLP response in the extra-tropical AMV forced experiment shows very high resemblance with 20CRv2.

- The analysis of the meridional temperature advection and the vertical structure of the geopotential height field reveal that the response from the negative extra-tropical AMV experiment shows similar characteristics of the observed NEW mode.

- The SAT response in the model from the positive AMV forced experiments shows negative anomalies over the C-E European region, which is opposite from the observed anomalies in decadal mean SATs as in Ghosh et al. (2017). 
- The SAT response over the C-E European region in the positive AMV phase experiments is mainly generated by the tropical branch of the AMV. The response has no similarity with the 20CRv2 and it could be due to the tropical part of the AMV in reality being atmosphere driven.

- The results for SLP, $500 \mathrm{hPa}$ geopotential height field, precipitation, and $200 \mathrm{hPa}$ velocity potential field strongly suggest that the tropical positive SST anomalies in the model tend to emanate a stationary Rossby wave response, which then propagates towards the extra-tropics. This creates an atmospheric condition, which advects colder polar winds towards C-E Europe and brings the negative SAT anomalies.

Altogether, we can conclude that the model SAT response over C-E Europe with the positive AMV forcing is opposite to what we have found in the reanalysis (Ghosh et al. 2017). However, in case of the negative AMV forcing, the model is indeed able to simulate the observed SAT response over the $\mathrm{C}-\mathrm{E}$ Europe and the related dynamical mechanism shows the characteristics of the observed linear baroclinic response to diabatic heating.

Acknowledgements Open access funding provided by Max Planck Society. This research is funded by the European Unions Seventh Framework Programme (FP7/20072013) under Grant agreement no. 308378 ENV.2012.6.1-1: Seasonal-to-decadal climate predictions towards climate services http://www.specs-fp7.eu/ and by the German Federal Ministry for Education and Research (BMBF) project MiKlip (Ref. No. 01LP1519A). This research is supported by the Cluster of Excellence 'CliSAP' (EXC177), University of Hamburg, funded through the German Science Foundation (DFG) and by the Max Planck Society for the Advancement of Science. The 20th Century Reanalysis V2 data is provided by the NOAA/OAR/ESRL PSD, Boulder, Colorado, USA, from their website http://www.esrl.noaa.gov/psd/. I am thankful to Ralf Hand for his valuable comments which helped improving the draft. I would like to thank the anonymous reviewers for their valuable inputs to help improve the paper.

Open Access This article is distributed under the terms of the Creative Commons Attribution 4.0 International License (http://creativeco mmons.org/licenses/by/4.0/), which permits unrestricted use, distribution, and reproduction in any medium, provided you give appropriate credit to the original author(s) and the source, provide a link to the Creative Commons license, and indicate if changes were made.

\section{References}

Brown PT, Lozier MS, Zhang R, Li W (2016) The necessity of cloud feedback for a basin-scale Atlantic multidecadal oscillation. Geophys Res Lett 43:3955-3963. https://doi.org/10.1002/2016G L068303

Compo GP, Whitaker JS, Sardeshmukh PD, Matsui N, Allan RJ, Yin X, Gleason BEJ, Vose RS, Rutledge G, Bessemoulin P, Bronnimann S, Brunet M, Crouthamel RI, Grant AN, Groisman
PY, Jones PD, Kruk MC, Kruger AC, Marshall GJ, Maugeri M, Mok HY, Nordli O, Ross TF, Trigo RM, Wang XL, Woodruff SD, Worley SJ (2011) The twentieth century reanalysis project. Q J R Meteorol Soc 137:1-28. https://doi.org/10.1002/qj.776

Davini P, von Hardenberg J, Corti S (2015) Tropical origin for the impacts of the Atlantic multidecadal variability on the EuroAtlantic climate. Environ Res Lett 10(9):094010. https://doi. org/10.1088/1748-9326/10/9/094010

Drews A, Greatbatch RJ (2016) Atlantic multidecadal variability in a model with an improved North Atlantic current. Geophys Res Lett 43:8199-8206. https://doi.org/10.1002/2016GL069815

Drews A, Greatbatch RJ (2017) Evolution of the Atlantic multidecadal variability in a model with an improved North Atlantic current. J Clim 30:5491-5512. https://doi.org/10.1175/JCLI-D-16-0790.1

Ghosh R, Müller WA, Baehr J, Bader J (2017) Impact of observed North Atlantic multidecadal variations to European summer climate: a linear baroclinic response to surface heating. Clim Dyn 48:3547-3563. https://doi.org/10.1007/s00382-016-3283-4

Gill AE (1980) Some simple solutions for heat-induced tropical circulation. Q J R Meteorol Soc 106:464-467

Gulev SK, Latif M, Keenlyside N, Park W, Koltermann KP (2013) North Atlantic Ocean control on surface heat flux on multidecadal timescales. Nature 499:464-467. https://doi.org/10.1038/ nature 12268

Hand R, Keenlyside N, Omrani NE, Latif M (2014) Simulated response to inter-annual SST variations in the Gulf Stream region. Clim Dyn 42:715-731. https://doi.org/10.1007/s00382-013-1715-y

Hodson DLR, Sutton RT, Cassou C, Keenlyside N, Okumura Y, Zhou T (2010) Climate impacts of recent multidecadal changes in Atlantic Ocean sea surface temperature: a multimodel comparison. Clim Dyn 34(7-8):1041-1058. https://doi.org/10.1007/s0038 2-009-0571-2

Hoskins BJ, Karoly DJ (1981) The steady linear response of a spherical atmosphere to thermal and orographic forcing. $\mathrm{J}$ Atmos Sci 38:1179-1196. https://doi.org/10.1175/15200469(1981)038<1179:TSLROA > 2.0.CO;2

Jungclaus J, Fischer N, Haak H, Lohmann K, Marotzke J, Matei D, Mikolajewicz U, Notz D, Storch J (2013) Characteristics of the ocean simulations in the Max Planck Institute Ocean Model (MPIOM) the ocean component of the MPI-Earth system model. J Adv Model Earth Syst 5(2):422-446. https://doi.org/10.1002/ jame. 20023

Kushnir Y (1994) Interdecadal variations in North Atlantic sea surface temperature and associated atmospheric conditions. J Clim 7:141157. https://doi.org/10.1175/1520-0442(1994)007<0141:IVINA $\mathrm{S}>2.0 . \mathrm{CO} ; 2$

Kushnir Y, Held IM (1996) Equilibrium atmospheric response to North Atlantic SST anomalies. J Clim 9(6):1208-1220. https:// doi.org/10.1175/1520-0442(1996)009<1208:EARTNA > 2.0.CO;2

Kushnir Y, Robinson WA, Blade I, Hall NMJ, Peng S, Sutton R (2002) Atmospheric GCM response to extratropical SST anomalies: synthesis and evaluation. J Clim 15:2233-2256. https://doi. org/10.1175/1520-0442(2002)015<2233:AGRTES > 2.0.CO;2

Rayner NA, Parker DE, Horton EB, Folland CK, Alexander LV, Rowell DP, Kent EC, Kaplan A (2003) Global analysis of sea surface temperature, sea ice, and night marine air temperature since the late nineteenth century. J Geophys Res 108(D14):4407. https:// doi.org/10.1029/2002JD002670

Rodwell MJ, Rowell DP, Folland CK (1999) Oceanic forcing of the wintertime North Atlantic Oscillation and European climate. Nature 398:320-323

Ruprich-Robert Y, Msadek R, Castruccio F, Yeager S, Delworth T, Danabasoglu G (2017) Assessing the climate impacts of the observed Atlantic multidecadal variability using the GFDL CM2.1 and NCAR CESM1 Global Coupled Models. J Clim 30:27852810. https://doi.org/10.1175/JCLI-D-16-0127.1 
Sardeshmukh PD, Hoskins BJ (1988) The generation of global rotational flow by steady idealized tropical divergence. J Atmos Sci 45:1228-1251

Scaife AA, Comer RE, Dunstone NJ, Knight J, Smith DM, MacLachlan C, Martin N, Peterson KA, Rowlands D, Carroll EB, Belcher S, Slingo J (2017) Tropical rainfall, Rossby waves and regional winter climate predictions. Q J R Meteorol Soc 143:1-11. https://doi. org/10.1002/qj.2910

Sutton RT, Hodson DL (2007) Climate response to basin-scale warming and cooling of the North Atlantic Ocean. J Clim 20(5):891907. https://doi.org/10.1175/JCLI4038.1

Sutton RT, Hodson DLR (2005) Atlantic ocean forcing of North American and European summer climate. Science 309(5731):115-118. https://doi.org/10.1126/science.1109496

Terray L, Cassou C (2002) Tropical Atlantic sea surface temperature forcing of quasi-decadal climate variability over the North Atlantic-European Region. J Clim 15:3170-3187. https://doi. org/10.1175/1520-0442(2002)015<3170:TASSTF $>2.0$.CO;2

Wang C, Zhang L, Lee SK, Wu L, Mechoso CR (2014) A global perspective on CMIP5 climate model biases. Nat Clim Change 4:201-205. https://doi.org/10.1038/NCLIMATE2118
Wu B, Lin J, Zhou T (2016a) Interdecadal circumglobal teleconnection pattern during boreal summer. Atmos Sci Lett 17:446-452. https ://doi.org/10.1002/asl.677

Wu B, Zhou T, Li T (2016b) Impacts of the pacific-japan and circumglobal teleconnection patterns on the interdecadal variability of the east asian summer monsoon. J Clim 29:3253-3271. https:// doi.org/10.1175/JCLI-D-15-0105.1

Wulff CO, Greatbatch RJ, Domeisen DIV, Gollan G, Hansen F (2017) Tropical forcing of the Summer East Atlantic pattern. Geophys Res Lett 44:11166-11173. https://doi.org/10.1002/2017GL0754 93

Yuan T, Oreopoulos L, Zelinka M, Yu H, Norris JR, Chin M, Platnick S, Meyer K (2016) Positive low cloud and dust feedbacks amplify tropical North Atlantic multidecadal oscillation. Geophys Res Lett 43:1349-1356. https://doi.org/10.1002/2016GL067679

Publisher's Note Springer Nature remains neutral with regard to jurisdictional claims in published maps and institutional affiliations.

\section{Affiliations}

\section{Rohit Ghosh ${ }^{1}(1) \cdot$ Wolfgang A. Müller ${ }^{2,3} \cdot$ Astrid Eichhorn $^{4} \cdot$ Johanna Baehr ${ }^{5} \cdot$ Jürgen Bader $^{2,6}$}

Wolfgang A. Müller

wolfgang.mueller@mpimet.mpg.de

Astrid Eichhorn

eichhorn@iau.uni-frankfurt.de

Johanna Baehr

johanna.baehr@uni-hamburg.de

Jürgen Bader

juergen.bader@mpimet.mpg.de

1 International Max Planck Research School for Earth System Modelling, Max Planck Institute for Meteorology, Hamburg, Germany
2 Max Planck Institute for Meteorology, Hamburg, Germany

3 Deutscher Wetterdienst, Hamburg, Germany

4 Goethe University Frankfurt, Frankfurt, Germany

5 Institute of Oceanography, University of Hamburg, Hamburg, Germany

6 Uni Climate, Uni Research and the Bjerknes Centre for Climate Research, Bergen, Norway 